\title{
Analysis on the Creative Themes of Chinese Writers in North America Under the Collision Between Chinese and Western Cultures
}

\author{
A Case Study of Chinese Writers in the 1960s and 1970s
}

\author{
Jiepei Chen \\ The Education University of Hong Kong \\ Hong Kong, China
}

\begin{abstract}
Under the background of the exchange of Chinese and Western cultural conflicts in the 20th century, the writing of the North American Chinese writers in the 1960s and 1970s presented a diversified character. They combine their own life experiences and survival feelings into the creative themes, and treat Western culture and thinking with a critical attitude, accompanied by more conscious reflection and understanding of Chinese traditional culture. Among them, the representative writers are $\mathrm{Yu}$ Lihua who is confused about the soil of spiritual survival, Yan Junling who is immersed in the pain and torture caused by cultural conflicts and eager to vent and liberate, and Tang Tingting who uses traditional cultural symbols to reconstruct the traditional China in order to integrate into the new country. This diversified exploration enriches the possibilities of Chinese writers' creation and promotes the exchange of Chinese culture and world culture.
\end{abstract}

Keywords-Chinese writers; Chinese and Western culture; creative theme

\section{INTRODUCTION}

The group of overseas Chinese writers first appeared in the period of the late Qing Dynasty and the early Republic of China. In the short period of 100 years associated with the pursuit of modernity in the modern Chinese nation, this group experienced the baptism of the thought trend, the turmoil of the political situation, the melting of society, so the characteristics of times has deeply written into the genes of this group. North America is the region with the largest number of overseas Chinese groups, many typical and representative writers have emerged, reflect the changing society and the attitude transformation towards Chinese and Western cultures in the era, due to the different societies, different times, as well as the differences in personal life experiences, the focused themes and the choices they made by different writers are also not the same.

Compared with the early writers who studied abroad, the North American Chinese writers who were active in the 1960s and 1970s had more complex social backgrounds, higher levels of education, and richer life experiences, so they were more determined and willing to continually try different styles and explore new expressions. They have experienced the dramatic changes in China and have more distinct personal qualities, so they described life less from a social perspective but more from personal experience, thus reflecting groups and times.

During this period, Chinese and Western cultures are no longer the early pure opposition relationship or the alternative of one or the other. Writers have raised their own doubts and tried ideas in the fusion of Chinese and Western cultures in their own works. They have different life states and thoughts, sometimes even completely opposite, but this does not affect their thinking and deepening of these issues. They began to treat Western culture and thinking with a critical attitude, accompanied by more conscious reflection and re-recognition of Chinese traditional culture. On the brand new road of ideological culture, literature and art exploring which built by a new era, they have received more praise and criticism, they bravely made their own choices in the form and content of creation, and thus made overseas Chinese writing presented with colorful and diversified features, which promote the overseas Chinese to create based on overseas and toward to the world, and finally integrated into the world and reach a new peak. Among them, the representative writers are $\mathrm{Yu}$ Lihua who is confused about the soil of spiritual survival, Yan Junling who is immersed in the pain and torture caused by cultural conflicts and eager to vent and liberate, and Tang Tingting who uses traditional cultural symbols to reconstruct the traditional China in order to integrate into the new country. They represent the different choices made by writers in this period in the context of the cultural differences and conflicts between China and the West.

\section{THE EXCLUSIVITY CONFUSED WITH WESTERN CULTURE}

In modern times, as more and more Chinese people went abroad and entered different foreign countries, other countries that were once "deified" gradually showed their true side. When the goers have a deeper understanding of Western culture and practice life abroad, as a member of the ethnic group with strong attribution and representativeness of skin color and culture, these overseas Chinese are very 
difficult to integrate into the Western society, the incompatibility for the new country and strangeness of the homeland made them enter a double isolation zone. Many people have doubts about their personal choices, they left their homeland to go to the "longing" country, but found that these places do not fully accept them. The confusion and lost feelings always surround them, and the conflicts and contradictions between Chinese and Western cultures are reflected, and then become the subject and focus of their creation.

$\mathrm{Yu}$ Lihua is a representative writer of this creative tendency. In the 1960s and 1970s, a large number of Chinese students in Taiwan studied abroad, most of them chose to stay in the foreign country, especially the United States after obtaining a certain degree of education, those who studied literature or engaged in literary creation also followed increased. For these people, academic, work, love, spiritual and life pressures from home and abroad are always entangled with racial discrimination and cultural conflicts, and become an intrinsic part of their lives and emotions. Mou Tianlei, the protagonist of "See Palms Again, See Palms Again" wrote by Yu Lihua, chose to teach in a local school after he obtained his $\mathrm{PhD}$. in the United States. It is clearly a stable and glamorous state of life in the eyes of others, but his feeling is "Behind him is a thousand pounds of stiff ice... He is burning with desperate anger and unwilling fire, slowly crawling, driving, and walking on the most lonely road of struggle in the world." ${ }^{1}$ This is because he seems to have a $\mathrm{PhD}$ degree in journalism and a decent job for college teachers, but in fact he did not really rank among the respected American middle class with this doctoral title. His job is only to "teach American college students who actually at the primary level how to pronounce, how to recognize the simplest Chinese characters". This kind of job did not have any satisfaction, and the American society at that time would not respect him, and it is disproportionate to his previous struggles and efforts. Therefore, he was puzzled by his study in the United States which followed by the trend and most people's choice. He began to doubt this seemingly beautiful decision and whether he considered it sufficiently clearly. Especially in the two months when he returned to his hometown, the envy and praise of the surrounding people compared to his humble and unmatched life that he actually lived made him struggle more. This work expresses a profound cultural reflection on the heat of studying abroad in the Chinese world at that time. At that time, many people just saw the glamorous appearance of studying abroad and the special experience that seemed to make life make further steps, but they do not know where the meaning and happiness behind this choice was. They clearly live abroad but because "the strong maternal culture makes them unequivocally indicate that they are Chinese in front of foreigners or personal resumes, but the strong impact of Western culture makes them unable to identify the maternal culture, during the conflicts they became the 'zero surplus' without roots." ${ }^{2}$ The double dilemma they face is that they have once pulled their self out from the soil of traditional China without hesitation, but found that the soil of a foreign land is not suitable and does not provide enough nutrition. A sense of drifting was pervaded in these people's lives.

\section{The PAIN CAUSED BY THE LOST IN THE CONFLICT BETWEEN CHINESE AND WESTERN CULTURE}

Due to the particularity of the times, the overseas Chinese community in this period experienced or witnessed many historical events. The pain and impressions brought by certain experiences in the chaotic society are eternal. This also represents the choice of some people in that particular era, Chinese traditional culture built their childhood, because of the decay and rigidity of Chinese traditional culture in the era, it brought more or less harm to them. For the new and completely different Western shocks, they yearn for and accept Western culture, but traditional culture is always lingering in their bones. Therefore, when they look back on their past experiences, they all have a complaint about their personal experiences and times, as well as some strong emotional experiences. The love and hate of maternal culture and foreign culture are presented in a rather complicated state, or huge resentment, or a huge loss.

Among them, Yan Junling's autobiographical novel "Foliage Return to Roots" is the most representative work. Yan Junling was born in a wealthy home of Tianjin in the 1930s, her step-mother kept transfer power in the family for her own interest, and only treated her own children well, so she was mean to the author in her childhood. Her stepmother was an typical example of the self-interested in traditional feudal culture and the product of specific marriage system, she represents the most backward and decaying part of traditional Chinese culture. In contrast, her aunt (father's younger sister), who was a new independent woman influenced by modern thoughts, has been quietly supporting the author from behind, teaching her independence and giving her comfort and spiritual support. These two completely opposite attitudes occupied the first half of the protagonist's life. The traditional Chinese marriage system and family culture concept are rooted in her family, "On the eve of her grandmother's wedding, her father called her to the front and said, 'Tomorrow you will be a member of Yan's family, from now on, here is no longer your home, you cannot contact us without your husband's permission. Your duty is to make your husband's family happy and have many boys. You should throw away the selfish distractions and be willing to be the punching bag and the garbage bin of the Yan family. We will be proud of you.' "3. This concept of treating women in extremely unfair way was inherited by her step-mother and was used and calculated to make the author's childhood life heavy and gloomy. Her step-mother's cruel heart and spiritual cold violence became the lingering harm to author's heart. And her aunt was the belief and brightness that lighted her dark past, supporting her to leave this suffering place and go to the United States to pursue the life she wants. However, despite this, the authors who survive in the gap between Chinese and Western cultures have far more complex and confused cultural feelings than we think. On one hand, she opposes the concept and system of multiple wives in traditional Chinese society. These decaying elements represented by her step-mother have given her childhood memories of eternal pain; but on the other hand, under the influence of her aunt who represents the modern culture of the West, she was long for the equal 
freedom in Western culture and finally got what she wanted through her lifetime struggle, but her final wish was to gain the recognition from her step-mother and traditional family, and reintegrate herself into the family ethical order of traditional culture. The reason for this seemingly unexpected change in attitude is that when she faced the cold violence of her American husband's family and plunged into the pressure of divorce and family breakdown after many years, parental support and traditional family values easily touched her: She re-discovered the indelible meaning of family ethics in traditional culture. By writing such a story, the author vented the mental torture she suffered over the years, mourning for her own emotions nowhere to put and for most of the life that cannot be erased.

\section{USE CUltural SyMbOLS TO RECONSTRUCT THE TRADITIONAL CHINESE CULTURAL IMAGE}

The overseas Chinese community has developed to this stage, many first generation immigrants have nurtured the second generation immigrants. They are far away from China's mainland, grow in exotic areas, and accept complete foreign thoughts. In this generation of Chinese writers, traditional China has become a symbol and mark that lives in their parents' mouths, and what they can and try to do is to constantly carry out these Chinese cultural symbols through their own unique perspectives, dismantle and integrate it into the core of Western culture for cultural reconstruction. Tang Tingting is one of the most representative writers who have achieved very high literary achievements in her country. As a "Chinese second generation" of American Chinese, her understanding of Chinese traditional culture is not reliable and accurate, she is best at the accumulation and re-creation of some typical Chinese elements. Her works often use her own imagination and unique writing perspectives and patterns to split the well-known Chinese stories that she heard from the parents, and then add to the core or spiritual tendencies of Western culture, thus created a number of specious cultural images which covered with Chinese traditional culture coat, but very suitable for the American spirit, they have a typical Chinese appearance or living environment, but actually talk about some current trends in the West. She likes to use and mix some heroes from different regions in different periods, such as Hua Mulan, Meng Jiangnv, Yue Fei, Guan Yu, Cao Cao, etc., but replace the spirit or ideological connotation of Chinese traditional culture, and mixed with some Western story cores and spirits, "Gathered people from different eras and different regions on the same stage" 4 . In her work "Women Warrior", the figure "Mulan" which represents the national spirit of loyalty and

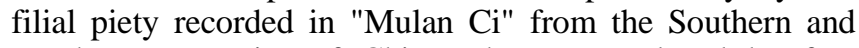
Northern Dynasties of China, she was replaced by free thought and self-worth pursue in the American spirit. This "Mulan" is not real "Mulan", in this story, she is not a girl who dressed like a man for her family, but a Chinese person who can open up in the inclusive society of the United States and seek a suitable way out and a foreseeing bright future, is a representative of the entire ethnic group that can save the entire difficult life of living in a foreign country for survival and life.
It is conceivable that such a creative tendency often causes the writers or works to appear on the cusp of the wind, and subject to the constant controversy and doubts from the media and academic circles. Many scholars believe that this form of expression is a misinterpretation, distortion and utilization of Chinese traditional culture. On the contrary, some people think that this is a re-creation and extension of Chinese traditional culture, using Chinese elements as the core and make further extending, it is a kind of greater progress and a feasible attempt to move Chinese culture into the world.

\section{CONCLUSION}

The North American Chinese writers of the 1960s and 1970 s, inherited the theme of early overseas Chinese creation, demonstrated their unique lifestyle and survival experience to the people of the world with their unique identity. They followed the traditional Chinese culture and the modern Western culture, through their own works which produced by their understanding of the two cultures and the intersection of the two cultures, which left a strong stroke in the world literature. Compared with the early overseas Chinese creation, their creation and thinking incorporate more personal experiences and survival feelings, including both the cold criticism of Western culture and the reflection and reconstruction of traditional Chinese culture. They abandoned the simple pattern of duality between the early writing and the simple opposite mode of Chinese and Western cultural issues, which made their works open and diversified, touched the complex and delicate human depth, and also made a useful and necessary foundation for the future generation to broke through the cultural comparison and further enhanced the creative theme to the superhuman human level.

\section{REFERENCES}

[1] [US] Yu Lihua. "See Palm Again,See Palm Again" [M]. Jiangsu Literature and Art Publishing Company, 2010.

[2] Li Hongxia. "Analysis of the "root" of "See Palm Again,See Palm Again" [J]. Journal of Huaibei Vocational and Technical College 2011.

[3] [US] Yan Junling, "Foliage Back to Roots" [M]. China Friendship Publishing Company, 2003.

[4] Tang Tingting, Translated by Li Jianbo, Lu Chengyi. "Women Warrior" [M].Lijiang Publishing Company, 1998.

[5] Xu Gang. "A Study of the Evolution of Chinese American Literature Discourse in a Multicultural Context" [D]. Jilin University, 2016.

[6] Yang Lijuan. The Cultural Evolution of "New Immigrant Literature" [J]. Journal of Henan Textile College, 2007.

[7] Li Xiaoxuan. "Where to find a way back home- Interpretation of $\mathrm{Yu}$ Lihua's novel <See palm again, see palm again" [J].Journal of Language and Literature (educational edition), 2010.

[8] Liu Lili. "MaYan Junling and the Miscellaneous Embodiment of Her Works" [D]. Hebei Normal University, 2008.

[9] Tang Tingting, Translated by Zhao Fuzhu, Zhao Wenshu. "Monkey King" [M]. Guangxi: Lijiang Publishing Company, 1998.

[10] Tang Tingting, translated by Xiao Suozhang. "Chinese" [M]. Shanghai Yilin Press, 2000.

[11] Yan Bihong, Zheng Jing, Wei Ting. "Deconstruction and Construction: A Misunderstanding of Chinese Culture in Tang 
Tingting's Works" [J]. Journal of Heilongjiang University of Technology (Comprehensive Edition), 2016.

[12] Qian Lianyu. "Intercultural Interpretation of Tang Tingting < Women Warrior>" [J]. Journal of Beijing Electric College, 2012. 